\title{
PERÍCIA PSIQUIÁTRICA EM TEMPOS DE COVID-19
}

\section{FORENSIC ASSESSMENT IN TIMES OF COVID-19}

A perícia médica se caracteriza por um conjunto de procedimentos técnicos cujo objetivo é esclarecer um fato de interesse da justiça, e o perito é o técnico incumbido pela autoridade de esclarecer o fato da causa, auxiliando, desse modo, na formação de convencimento de autoridade judicial. Dessa forma, a perícia é um meio de prova, e o perito, um auxiliar do juiz ${ }^{1}$.

Entre os vários meios produtores de prova no direito, a perícia se destaca como um meio especial, na qual o concurso de um profissional especialista na área em questão faz-se necessário para o esclarecimento de fatos técnicos, que no âmbito do processo civil se dá através de exame, vistoria ou avaliação².

Em psiquiatria, os principais tipos de perícia são a criminal (imputabilidade penal), a ser realizada quando há dúvidas sobre a sanidade mental de um indivíduo acusado de ter cometido um delito; a cível, que irá avaliar a capacidade do indivíduo de exercer direitos da vida cível, como administrar bens e negócios; e a administrativa, cuja finalidade é avaliar a capacidade laborativa de indivíduos, inclusão de dependentes, avaliação quanto ao direito a benefícios, como licenças médicas, aposentadorias, etc.

No Brasil, a pandemia do COVID-19 acarretou diversas mudanças nas relações sociais, devido à necessidade de isolamento, de forma a diminuir o contágio da virose entre as pessoas ${ }^{3}$. Essas mudanças também têm afetado o campo da medicina, inclusive as intervenções relacionadas a cuidados clínicos, terapêuticos e avaliações periciais.

No ano de 2020, Conselho Federal de Medicina (CFM), conforme o Artigo $3^{\circ}$ da Lei $n^{\circ} 13.989 / 20^{4}$, reconheceu a possibilidade da prática da telemedicina no país, em caráter excepcional, enquanto durar a situação de emergência em saúde pública. Telemedicina é o exercício da medicina a distância, com médico e paciente se comunicando por videoligações de aplicativos, como WhatsApp e Skype.
No que diz respeito a teleperícias, o CFM, em parecer realizado em março de $2020^{5}$, estabeleceu que "o médico perito judicial que utiliza recurso tecnológico sem realizar o exame direto ao periciando afronta o Código de Ética Médica e demais normativas emanadas do Conselho Federal de Medicina". Ainda de acordo com esse parecer, o uso de recursos de telemedicina é admissível em junta médica pericial, quando, de um lado, está o médico perito a realizar o exame físico no periciando e, a distância, os outros médicos peritos acompanham todo o ato pericial, sendo que juntos assinam o laudo pericial.

É sabido que no Brasil existe uma população com altos níveis de pobreza e vulnerabilidade social, agravados pela pandemia de COVID-19, que trouxe taxas maiores de desemprego e falta de assistência em saúde, em geral. Essa problemática certamente foi acompanhada de maiores demandas ao sistema de previdência social no Brasil.

Reconhecendo a problemática social e humanitária trazida pela pandemia, o Conselho Nacional de Justiça aprovou, em 28/4/2020, a Resolução n 00316232.2020.2.00.0000 ${ }^{6}$, que autoriza a realização de perícias médicas por meios eletrônicos ou virtuais, em ações previdenciárias, com fins de concessão de benefícios previdenciários por incapacidade ou assistenciais, enquanto durar a pandemia. Essa resolução orienta que o requerente deve autorizar o procedimento, informar endereço eletrônico e número de celular a serem utilizados durante a realização do procedimento, bem como juntar aos autos os documentos necessários, a exemplo de laudos, relatórios e exames médicos, fundamentais para subsidiar o laudo pericial. $\bigcirc$ ato normativo explicita ainda que os procedimentos que eventualmente não puderem ser realizados por meio eletrônico, por absoluta impossibilidade técnica ou prática a ser apontada por quaisquer dos envolvidos, devem ser devidamente justificados nos autos e comunicados oficialmente. 
É importante destacar que uma leitura isolada do $\$ 4^{\circ}$ do Art. 464 do Código de Processo Civil (CPC) ${ }^{2}$ induz - leitor a entender que a teleperícia estaria autorizada na legislação processual civil, ao prever a possibilidade do uso de "recurso tecnológico de transmissão de sons e imagens". No entanto, é importante ressaltar que referido dispositivo não se aplica à prova pericial, haja vista que, interpretando-o conjuntamente com o $\$ 3^{\circ}$ do Art. 464 do CPC, percebe-se que a utilização de "recurso tecnológico de transmissão de sons e imagens" é específica apenas para "prova técnica simplificada", estando esta limitada à simples oitiva do especialista pelo juiz; logo, não há qualquer participação e/ou exame e/ou avaliação do paciente/pessoa partícipe do processo, nem é produzido um laudo pericial para auxiliar na convicção do juízo, mas tão somente é colhido depoimento técnico do profissional com formação acadêmica específica para a questão controvertida no processo.

Nos $\S \S 3^{\circ}$ e $4^{\circ}$ do Art. 464 do CPC temos o seguinte:

\begin{abstract}
Art. 464. A prova pericial consiste em exame, vistoria ou avaliação.

$\S 3^{\circ}$ A prova técnica simplificada consistirá apenas na inquirição de especialista, pelo juiz, sobre ponto controvertido da causa que demande especial conhecimento científico ou técnico.

$\S 4^{\circ}$ Durante a arguição, o especialista, que deverá ter formação acadêmica específica na área objeto de seu depoimento, poderá valer-se de qualquer recurso tecnológico de transmissão de sons e imagens com o fim de esclarecer os pontos controvertidos da causa.
\end{abstract}

A ciência médica forense não subsiste sem o contato/exame físico com o periciado, em decorrência tanto da exigência legal processual de "indicação do método utilizado, esclarecendo-o e demonstrando ser predominantemente aceito pelos especialistas da área do conhecimento da qual se originou"2, quanto da exigência legal do Código de Ética Médica7, que veda expressamente a assinatura de laudos periciais sem a realização do exame físico pessoalmente.

Não podemos deixar de considerar que a perícia psiquiátrica tem suas características peculiares, iniciando desde o comparecimento (se acompanhado ou sozinho) do periciando na sala de espera, sua forma de andar, vestir-se, higiene pessoal e o modo de interação social com o perito e/ou acompanhantes e pessoas na sala de espera. Todos esses aspectos dificultam extremamente a avaliação não presencial. Além do exame físico, o perito psiquiatra deverá estar muito atento em relação à expressão e mímica facial, à tonalidade da fala, aos gestos e aos movimentos corporais, sendo que todos esses poderão ficar artificializados em uma avaliação por telemedicina, distorcendo, dessa forma, a percepção da correta semiologia psiquiátrica e acuidade do laudo pericial. As reações transferenciais e contratransferenciais que se passam no setting forense presencial são igualmente importantes ${ }^{8}$.

Outros aspectos importantes são o sigilo processual, que pode ser facilmente quebrado em uma avaliação por telemedicina, e o estabelecimento de nexo causal. Uma visão parcial, como a que pode acontecer em uma avaliação por telemedicina, pode levar o perito a analisar um fenômeno complexo, isolando algumas poucas variáveis e decidindo a partir dessa separação, havendo maior probabilidade de uma conclusão pericial equivocada?.

Nesse cenário, em que pese a louvável iniciativa de superar as barreiras impostas pelo isolamento social, não se pode olvidar que o perito nomeado pelo juízo exerce função essencial à administração da justiça, sendo que - laudo pericial muitas vezes é a prova determinante para procedência dos pedidos do periciado, de forma que o exame físico para constatação inequívoca do dano mediante a avaliação de capacidade laborativa, de aptidão ou inaptidão para o trabalho (valoração do dano) é imprescindível para a segurança jurídica dos partícipes e a estabilidade social do processo.

A Associação Brasileira de Psiquiatria acredita que o melhor a ser feito é seguir os ditames do Código de Ética Médica9 e o parecer estabelecido pelo CFM ${ }^{5}$, solicitando remarcação de laudos periciais até que seja possível a avaliação presencial.

Artigo submetido em 30/08/2020, aceito em 30/08/2020. Os autores informam não haver conflitos de interesse associados à publicação deste artigo.

Fontes de financiamento inexistentes.

Correspondência: Alexandre Martins Valença, Rua Conde de Bonfim, 232, sala 511, Tijuca, CEP 20520054, Rio de Janeiro, RJ. E-mail: avalen@uol.com.br 


\section{Referências}

1. Taborda JGV, Castro Bins HD. Exame pericial psiquiátrico. In: Abdalla-Filho E, Chalub M, Telles LEB. Psiquiatria forense de Taborda. São Paulo: Artmed; 2016. p. 35-70.

2. Brasil. Lei no 13.105, de 16 de março de 2015. Código de Processo Civil. http://www.planalto. gov.br/ccivil_03/_Ato2015-2018/2015/Lei/ L13105.htm

3. de Borba Telles LE, Valença AM, Barros AJ, da Silva AG. Domestic violence in the context of the COVID-19 pandemic: a forensic psychiatric perspective. Braz J Psychiatry. 2020 Jun 1;S151644462020005015211. doi:10.1590/1516-44462020-1060. Online ahead of print.

4. Brasil. Lei $n^{\circ}$ 13.989, de 15 de abril de 2020 . in.gov.br/en/web/dou/-/lei-n-13.989-de-15-deabril-de-2020-252726328

5, Conselho Federal de Medicina (CFM). Parecer do CFM veda prática de teleperícias ou perícias virtuais sem exame direto [Internet]. $2020 \mathrm{Apr}$ 23 [cited 2020 Oct 9]. portal.cfm.org.br/index. php?option $=$ com_content $\&$ view $=$ article $\&$ id $=2867$ $0: 2020-04-23-11-42-43 \&$ catid $=3$

6. Conselho Nacional de Justiça (CNJ). Covid-19: resolução autoriza perícia previdenciária por meio eletrônico [Internet]. 2020 Apr 30 [cited 2020 Oct 9]. cnj.jus.br/covid-19-resolucao-autorizapericia-previdenciaria-por-meio-eletronico/

7. Conselho Federal de Medicina (CFM). Código de ética médica. Resolução Nº 2217 de 27/09/208. portal.cfm.org.br/images/PDF/cem2019.pdf

8. Dalgalarrondo P. A entrevista com o paciente. In: Dalgalarrondo P. Psicopatologia e semiologia dos transtornos mentais. Porto Alegre: Artmed; 2008. p. 66-84.

9. Epiphanio EB, Xavier Vilela JRP. Particularidades da perícia médica. In: Epiphanio EB, Xavier Vilela JRP. Perícias médicas - teoria e prática. Rio de Janeiro: Guanabara Koogan; 2009. p. 14-23. 